\title{
Realgar, a traditional Chinese medicine, induces apoptosis of HPVI6-positive cervical cells through a HPVI6 E7-related pathway
}

This article was published in the following Dove Press journal: Drug Design, Development and Therapy

\author{
Wencheng Dingl,* \\ Teng Ji ${ }^{1}$,* \\ Wei Xiong ${ }^{2}$ \\ Tian $\mathrm{Li}^{\prime}$ \\ Demin Pu' \\ Rong Liu'
}

'Department of Obstetrics and Gynecology, Tongji Hospital, Tongji Medical College, Huazhong University of Science and Technology, Wuhan, Hubei, People's Republic of China; ${ }^{2}$ Department of Pharmacology, Tongji Hospital, Tongji Medical College, Huazhong University of Science and Technology, Wuhan, Hubei, People's Republic of China

*These authors contributed equally to this work
Correspondence: Rong Liu Department of Obstetrics and Gynecology, Tongji Hospital, Tongji Medical College, Huazhong University of Science and Technology, 1095 Jiefang Road, Wuhan, Hubei 430030, People's

Republic of China

Tel/fax +862783662663

Email liurongdoctor@163.com
Purpose: In this study, we investigated the effect of Realgar on the apoptosis of HPV16positive cervical cells in vitro.

Methods: The effect of Realgar on the apoptosis of HPV16-positive cervical cells was investigated by annexin V-fluorescein isothiocyanate/propidium iodide staining and growth inhibition assays using HPV16-positive cervical cancer cell line SiHa and HPV16-positive immortalized cervical epithelial cell line S12. The expression of genes was measured by real-time PCR, and the expression of corresponding proteins was detected by Western blotting. The adhesion and invasion of cells were detected by adhesion assay and Transwell invasion assay, respectively. Results: The Realgar inhibited the proliferation and induced the apoptosis of SiHa and S12 cells in a dose- and time-dependent manner. The Realgar suppressed the expression of HPV16 E7 and caspase-3. The Realgar suppressed the adhesion and invasion of both cells.

Conclusion: The Realgar induced apoptosis, inhibited the proliferation of HPV16-positive cell lines through a HPV16 E7-dependent pathway, and inhibited cell adhesion and invasion.

Keywords: Realgar, antitumor, human papillomavirus, E7

\section{Introduction}

Cervical cancer remains the fourth most common malignant cancer in woman worldwide, with $\sim 527,600$ new cases and 265,700 deaths annually. ${ }^{1}$ According to "Cancer Statistics in China, 2015", $\sim 98,900$ new cases of cervical cancer are diagnosed annually, resulting in $>30,500$ deaths in China, ${ }^{2}$ while there are 13,240 new cases of cervical cancer, resulting in 4,170 deaths in the United States. ${ }^{3}$ Although early screening program improves the early diagnosis rate, radical surgery for early stages supplemented by chemotherapy and radiotherapy prolongs the overall survival significantly and many patients only receive incomplete therapy because of the lack of money. Therefore, a new effective and economic strategy for the treatment of cervical cancer is urgently needed.

In China, the traditional Chinese medicine still plays an important role in the treatment of various diseases. The traditional Chinese medicine Realgar (mainly $\mathrm{As}_{4} \mathrm{~S}_{4}$, tetraarsenic tetrasulfide) has been used well in the treatment of both internal and external diseases, such as infection, inflammation, fever, and convulsion, even some skin disease. ${ }^{4,5}$ The relative safety, sufficient resources, and convenient application means Realgar has gained more attention in the treatment of many diseases, and Realgar has been proved to have obvious therapeutic activities in several cancers, especially acute promyelocytic leukemia (APL) ${ }^{6-8}$ Ding W, et al has confirmed that its antitumor effect 
is correlated with its ability to induce apoptosis and inhibit cell proliferation. ${ }^{9}$

It has been reported that Realgar showed antitumor activities in various solid tumor cell lines, such as hepatocellular carcinoma HepG2 cells, malignant melanoma A375 cells, pancreatic carcinoma 8898 cells, and gastric cancer MKN45 cells. ${ }^{9}$ The main mechanism of antitumor effect based on the induction of apoptosis and inhibition of proliferation of the cells. To further investigate the cytotoxic effect and the molecular mechanism of Realgar in cervical cell lines, we select HPV16-positive cervical cancer cell line $\mathrm{SiHa}$ and human papillomavirus (HPV)-positive immortalized cervical epithelial cell line S12. We found that Realgar exhibited potent induction of apoptosis effects in both cell lines and the molecular biological experiments confirmed that the effect of Realgar on both SiHa and S12 cell lines was based on both the upexpression of Bcl-2 and downexpression of HPV16 E7, Bax, and caspase-3. This process was unlike the effect of Realgar in gastric cancer cells, which induced apoptosis through a P53-dependent pathway. ${ }^{10,11}$ These results indicated that Realgar induces apoptosis and inhibits proliferation in HPV16-positive cell lines through a HPV16 E7-dependent pathway and a P53-independent pathway.

\section{Materials and methods Cell culture}

Cervical cancer cell line SiHa was purchased from American Type Culture Collection (ATCC) (Manassas, VA, USA) and maintained in DMEM supplemented with $10 \% \mathrm{FBS}$ at $37^{\circ} \mathrm{C}$ in a humidified incubator with $5 \% \mathrm{CO}_{2}$. S12, a HPV16-positive immortalized human cervical keratinocytes' cell line, was a generous gift from Professor Kenneth Raj (Health Protection Agency), and the acquisition was permitted by the original owner Professor Margaret Stanley. ${ }^{12} \mathrm{~S} 12$ was maintained in a 1:3 mixture of DMEM and Ham F-12 supplemented with FBS $(5 \%)$, cholera toxin $(8.4 \mathrm{ng} / \mathrm{mL})$, insulin $(5 \mathrm{mg} / \mathrm{mL})$, adenine $(24.3 \mathrm{mg} / \mathrm{mL})$, hydrocortisone $(0.5 \mathrm{mg} / \mathrm{mL})$, and recombinant human epidermal growth factor $(10 \mathrm{ng} / \mathrm{mL})$. The experiments were performed three times in duplicate.

\section{Reagents}

Realgar was purchased from the Hubei Pharmacy Ltd. (Wuhan, China). The purity of arsenic sulfide $\left(\mathrm{As}_{4} \mathrm{~S}_{4}\right)$ was $92.3 \%$. A total of $3 \mathrm{~g}$ of Realgar sample was screened through 500 screen mesh, supplemented with distilled water to reach $300 \mathrm{~mL}$, and agitated with magnetic stirrer for 30 minutes, then it was added into M-110EH micro-aspirating gas stream granulator (Shanghai Liyue Sophisticated Machinery Commercial Ltd., Shanghai, China), at 30,000 rpm, 10 cycles, then subjected to ultrasonic vibration for 30 minutes and degermed via $0.22 \mu \mathrm{m}$ micropore filter, stored airtightly and protected from light at $4{ }^{\circ} \mathrm{C}$. The concentration of Realgar was determined by using spectrophotometry, and the particle size was detected with Nicomp 380 ZLS particle sizing determination meter (Particle Sizing Systems, Florida, USA). The particle size used in this study ranged from 74.38 to $437.31 \mathrm{~nm}$, with the average size of $186.81 \pm 27.37 \mathrm{~nm}$. The Realgar was diluted to working concentrations with 1.5\% fetal bovine serum-containing DMEM (Thermo Fisher Scientific, Waltham, MA, USA).

\section{Apoptosis assay}

Cells were harvested and incubated with annexin V-fluorescein isothiocyanate (FITC) and propidium iodide (PI) using an Annexin V-FITC Apoptosis Detection Kit (KeyGEN BioTech, Nanjing, China) following the manufacturer's instruction. After staining for 30 minutes at $4^{\circ} \mathrm{C}$, the cells were detected using the BD FACSCalibur flow cytometer and analyzed by the CellQuest ${ }^{\mathrm{TM}}$ Pro software (BD Biosciences, San Jose, CA, USA).

\section{Cell proliferation assay}

The cell proliferation on SiHa and S12 cells exposed to Realgar was determined by the cell counting kit-8 assay (CCK-8; Dojindo, Shanghai, China), according to the manufacturer's manual. Briefly, $2 \times 10^{3}$ of SiHa and S12 cells were seeded in 96-well plates and cultured overnight. Cells were incubated with various concentrations of Realgar for indicated times. CCK-8 solution was added to each well to a final concentration of $10 / 100 \mu \mathrm{L}$ medium and incubated for 2 hours at $37^{\circ} \mathrm{C}$ in dark. The absorbance was detected at $450 \mathrm{~nm}$ using a microplate reader (SpectraMax ${ }^{\circledR} 190$; Molecular Devices LLC, Sunnyvale, CA, USA).

\section{Real-time PCR}

Total RNA was isolated using the Qiagen RNeasy kit following the manufacturer's instructions. Quantitation of RNA was determined using a NanoDrop microvolume spectrophotometer (Thermo Fisher Scientific). Reverse transcription was then performed using the Prime Script RT-PCR Kit (Takara Bio Inc., Beijing, China) according to the manufacturer's instructions. Quantitative RT-PCR was performed in a CFX96 Touch $^{\text {TM }}$ Real-Time PCR Detection System (Bio-Rad Laboratories Inc., Hercules, 
CA, USA) using the following thermocycler program for all genes: 5 minutes of preincubation at $95^{\circ} \mathrm{C}$ followed by 40 cycles of 15 seconds at $95^{\circ} \mathrm{C}, 15$ seconds at $60^{\circ} \mathrm{C}$, and 30 seconds at $72^{\circ} \mathrm{C}$. The primers of all target genes and the reference gene are listed in Table S1.

\section{Western blot}

Cells were lysed on ice for 30 minutes with a lysis buffer containing $150 \mathrm{mmol} / \mathrm{L} \mathrm{NaCl}, 50 \mathrm{mmol} / \mathrm{L}$ Tris (pH 7.4), $1 \%$ Triton X-100, $1 \%$ sodium deoxycholate, $0.1 \%$ SDS, and protease inhibitor cocktail. Total proteins were extracted and resolved by $10 \%$ SDS-PAGE, transferred to polyvinylidene difluoride (PVDF) membranes (350 $\mathrm{mA}$ for 1 hour), and probed with antibodies against GAPDH (Proteintech, Wuhan, China), HPV16 E7 (sc-6981; Santa Cruz Biotechnology Inc., Dallas, TX, USA), P53, Caspase-3, bax, and Bcl-2 (Proteintech, Wuhan, China). Proteins were visualized using the horseradish peroxidase-conjugated secondary antibodies with SuperSignal West Pico Chemiluminescent Substrate (Pierce, Shanghai, China) and photographed in ChemiDoc ${ }^{\mathrm{TM}} \mathrm{XRS}+$ System with Image Lab ${ }^{\text {TM }}$ Software (Bio-Rad).

\section{Adhesion assay}

A 12-well plate was precoated with $1 \mathrm{~mL}$ of fibronectin $(5 \mu \mathrm{g} / \mathrm{mL})$ for 2 hours at room temperature. The cells were treated with various concentrations of Realgar for 48 hours and seeded into the coated plates at a density of $10^{5}$ cells/well and allowed to adhere at $37^{\circ} \mathrm{C}$ for 1 hour. Nonadherent cells were washed off with PBS, fixed in 4\% paraformaldehyde, and stained with Giemsa solution.

\section{Transwell invasion assay}

The invasion assay was performed in Transwell (Corning Incorporated, Corning, NY, USA) plates. The upper wells were coated with Matrigel (BD Biosciences) at $37^{\circ} \mathrm{C}$ for 1 hour in a $5 \% \mathrm{CO}_{2}$ incubator. The cells were treated with various concentrations of Realgar for 48 hours and then starved without serum for 24 hours, and then, $500 \mu \mathrm{L}$ of cell suspension containing $5 \times 10^{4}$ cells was seeded in the upper chamber. Culture medium supplemented with $10 \%$ FBS $(750 \mu \mathrm{L})$ was added into the lower chamber and incubated for 48 hours. After the incubation, the cells on the upper surface of the filter were wiped with a cotton swab. The migrated cells on the lower surface were washed with PBS, fixed in $4 \%$ paraformaldehyde, stained with $0.2 \%$ crystal violet, and observed under a microscope (magnification, $\times 100$ ). Cells were counted in the central field of triplicate membranes.

\section{Statistical analyses}

Statistical significance was determined by the unpaired Student's $t$-test using the GraphPad Prism software (Version 6.01). All data were expressed as mean \pm SD. Significance for all tests was set at $P<0.05$.

\section{Results}

\section{Realgar induced apoptosis and inhibited proliferation of $\mathrm{SiHa}$ cells}

To observe the potential effects of apoptosis induced by Realgar in human cervical cancer cells, SiHa cells were treated with different concentrations of Realgar $(0,12.5$, 25 , and $50 \mu \mathrm{g} / \mathrm{mL}$ ) for 24 hours. We found that incubation with $25 \mu \mathrm{g}$ of Realgar induced apoptosis significantly. After treating with $50 \mu \mathrm{g}$ of Realgar, we detected $>75 \%$ of apoptosis. The increase in apoptosis was consistent with the increase in the dosage of Realgar. These data indicated that Realgar induced concentration-dependent apoptosis of $\mathrm{SiHa}$ cells (Figure 1). Similarly, the incubation of SiHa cells with increasing concentrations of Realgar $(12.5-50 \mu \mathrm{g} / \mathrm{mL})$ at the indicated time points $(24,48$, and 72 hours) induced a timedependent increase in apoptosis. Overall, these data indicated that Realgar induced apoptosis and inhibited the proliferation of $\mathrm{SiHa}$ cells in a time- and concentration-dependent mode.

\section{Realgar induced apoptosis and inhibited proliferation of SI 2 cells}

To further explore the potential of apoptosis induced by Realgar, we treated S12 cells (a HPV16-positive immortalized cervical epithelial cells) with the indicated concentrations of Realgar $(0,12.5,25$, and $50 \mu \mathrm{g} / \mathrm{mL})$ for 24,48 , and 72 hours. Similar to data from SiHa cells, Realgar induced apoptosis in a time- and dose-dependent manner (Figure 2).

\section{Realgar suppressed the expression of HPV E7}

Since Realgar induced apoptosis and inhibited the proliferation of both SiHa and S12 cells, both the cells were HPV16 positive and expressed $E 6$ and $E 7$ genes. We evaluated the expression of HPV16 E7 and E6 mRNA in both SiHa and S12 cells treated with various concentrations of Realgar. We found that the expression of HPV16 E7 showed a significant decrease in SiHa and S12 cells treated with Realgar, especially in the groups with higher concentration, while we did not found any change in the expression of HPV16 E6 ( $P=0.01$, Student's $t$-test) (Figure 3 ). These data indicate 

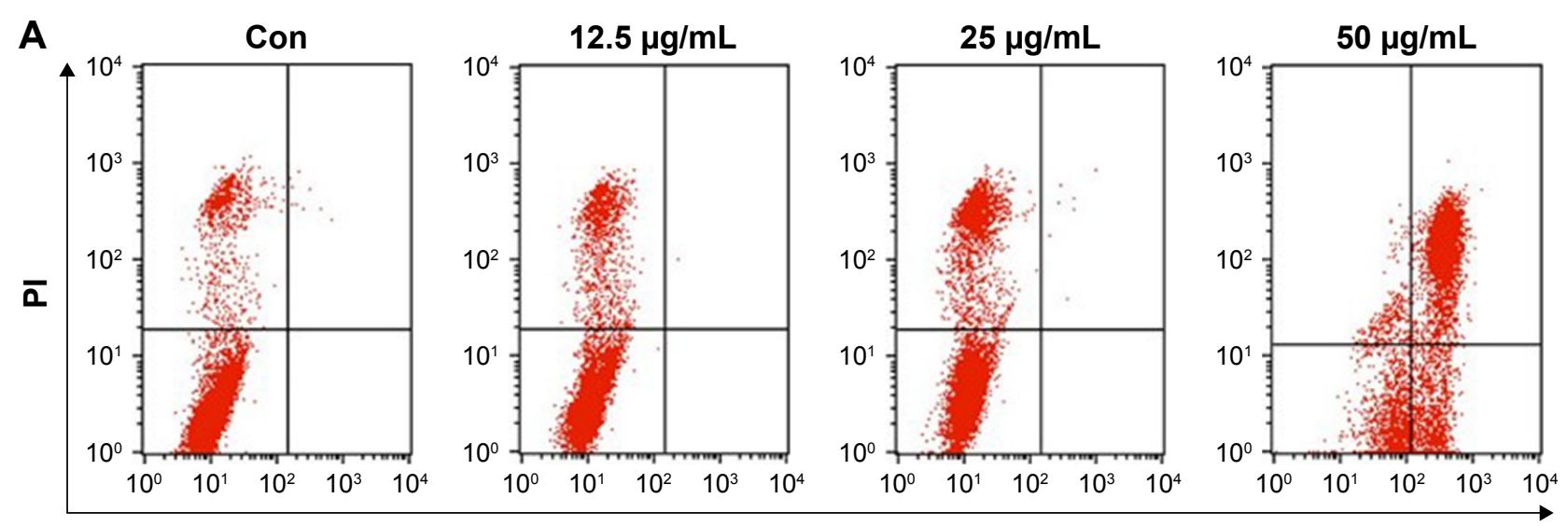

Annexin V-FITC

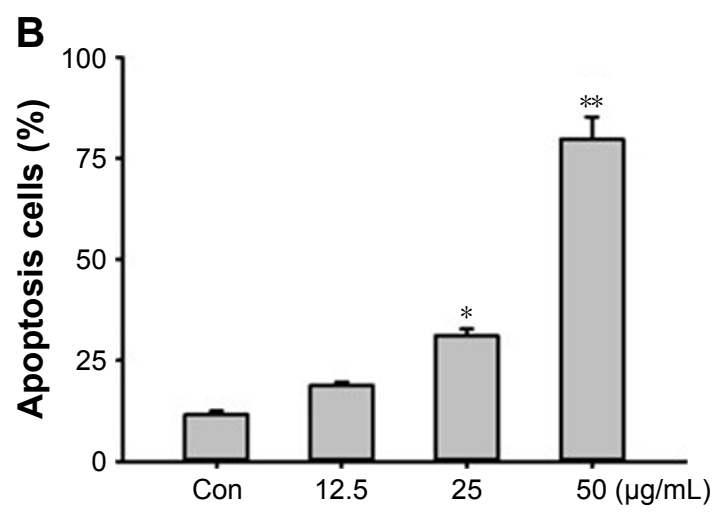

C

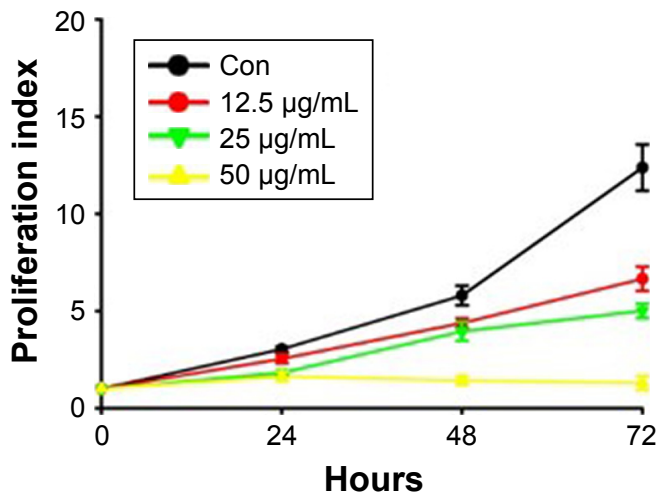

Figure I Effects of Realgar on the apoptosis and proliferation of SiHa cells.

Notes: SiHa cells were treated with various concentrations of Realgar for different times. (A) SiHa cells were incubated with Realgar at a dose ranging between I2.5 and $50 \mu \mathrm{g} / \mathrm{mL}$ for 24 hours and subjected to analysis by flow cytometric analysis. (B) The average percentages of apoptosis cells were reported in the graphs. Error bars: SD; $* P<0.05$; $* * P<0.01$ ( $n=3$ replications). (C) Quantitative analysis of the proliferation index determined by the CCK- 8 assay for the indicated times. The results shown are averaged through three separate experiments; error bars: $\mathrm{SD}$; $* P<0.05$.

Abbreviations: CCK-8, cell counting kit-8; Con, control; FITC, fluorescein isothiocyanate; PI, propidium iodide.

that Realgar inhibited the expression of HPV16 E7 within a certain concentration range.

\section{Realgar suppressed the expression of caspase-3 and upregulated the expression of $\mathrm{BCl}-2$}

To further explore the effects of Realgar in the regulation of apoptosis-related genes, we detected the expression of $\mathrm{Bax}$, Bcl-2, P53, and caspase-3. As shown in Figure 4, we found a significant decrease in Bax and caspase-3 in the SiHa cells treated with Realgar, even in those treated with lower dose $(12.5 \mu \mathrm{g} / \mathrm{mL})$ (Figure $4 \mathrm{~A}$ and D), and a significant increase in $B c l-2$ in the cells (Figure 4B), while the expression of P53 in $\mathrm{SiHa}$ cells incubated with various concentrations of Realgar seems irregular (Figure 4C). Similarly, we observed the same trends in S12 cells treated with corresponding concentration of Realgar (Figure 5). We detected a significant decreased expression in Bax and caspase-3 in S12 cells treated with
Realgar, especially with higher dosage of Realgar, and a significant increase in $B c l-2$. Meanwhile, we did not found any significant changes in P53 in S12 cells treated with Realgar. These data indicated that Realgar may induce cell apoptosis through a non-P53-dependent pathway.

\section{Realgar suppressed the expression of HPVI6 E7, Bax, and caspase-3 proteins}

To further investigate the effects of Realgar in the regulation of apoptosis-related proteins and HPV16 E7, we detected the protein expression of these proteins by Western blotting. As shown in Figure 6, after treating with different dosages of Realgar for 48 hours, the HPV16 E7 and Bax expressions were markedly downregulated. While Bcl-2, P53, and caspase-3 were substantially upregulated in lower dose $(25 \mu \mathrm{g} / \mathrm{mL})$ and downregulated in higher dosage $(50 \mu \mathrm{g} / \mathrm{mL})$. The expression of HPV16 E6 was constant in both the cells. 

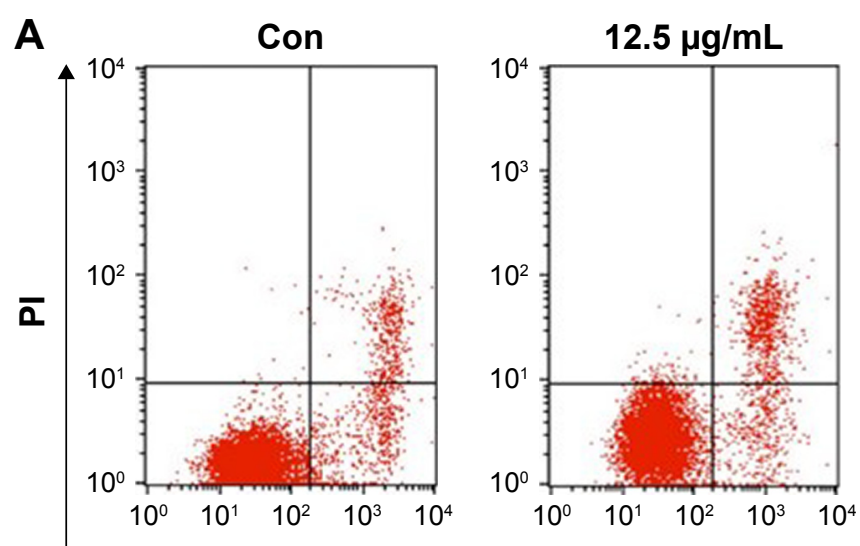
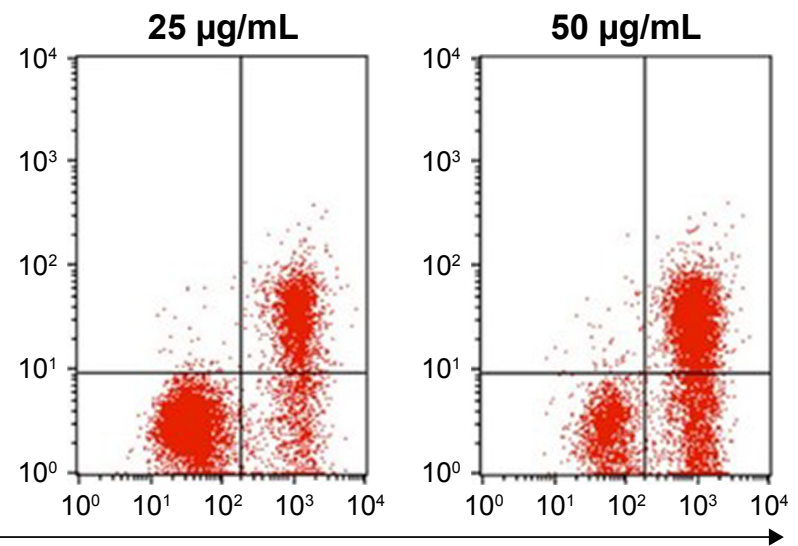

\section{Annexin V-FITC}
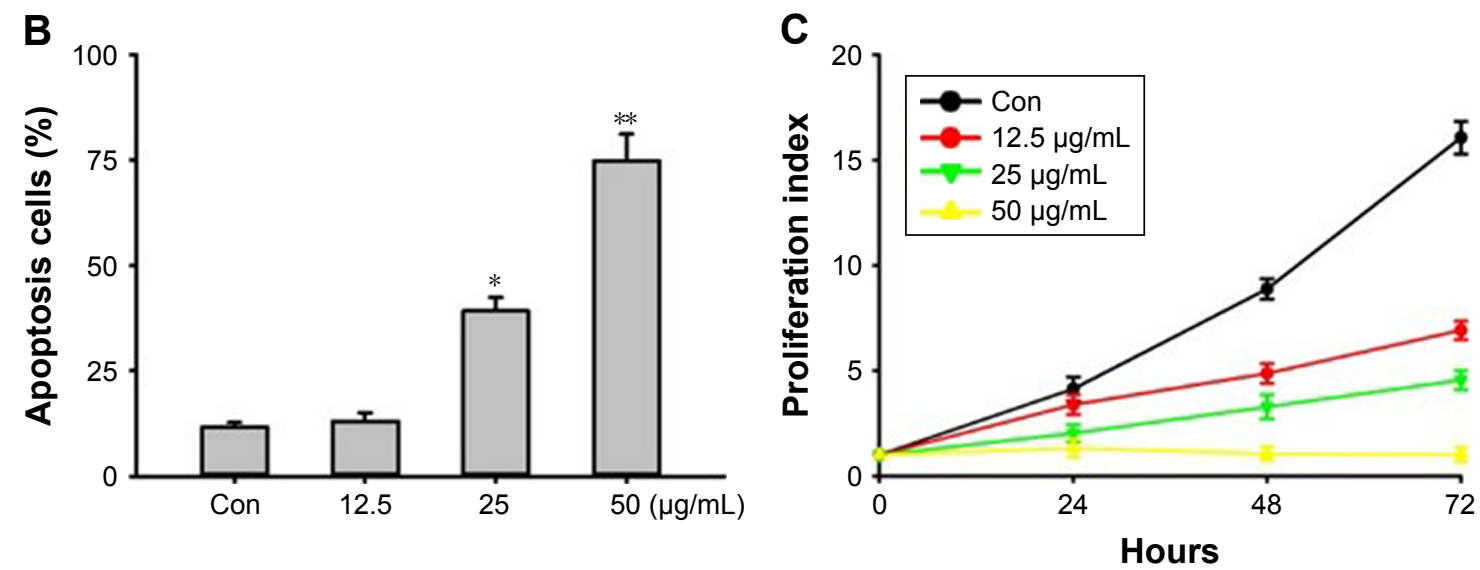

Figure 2 Effects of Realgar on the apoptosis and proliferation of SI 2 cells.

Notes: SI 2 cells were treated with various concentrations of Realgar for different times. (A) SI 2 cells were incubated with Realgar at a dose ranging between 12.5 and $50 \mu \mathrm{g} / \mathrm{mL}$ for 24 hours and subjected to analysis by flow cytometric analysis. (B) The average percentages of apoptosis cells were reported in the graphs. Error bars: SD; $* P<0.05 ; * *<0.01$ ( $n=3$ replications). (C) Quantitative analysis of the proliferation index determined by the CCK-8 assay for the indicated times. The results shown are averaged through three separate experiments; error bars: SD; $* P<0.05$.

Abbreviations: CCK-8, cell counting kit-8; Con, control; FITC, fluorescein isothiocyanate; PI, propidium iodide.

\section{Realgar suppressed adhesion and invasion of cells}

To further check the biological effects of Realgar, the cell adhesion and invasion capacity were evaluated by cell adhesion and Matrigel-coated membrane chamber invasion assays. The adherent ability of both $\mathrm{SiHa}$ (Figure 7A) and S12 (Figure 7B) cells was significantly repressed by Realgar. The numbers of adherent cells were significantly decreased after treating with Realgar in both $\mathrm{SiHa}$ and $\mathrm{S} 12$ cells. Similarly, as shown in Figure 7C and D, a radical reduction in the invasive ability was shown in both $\mathrm{SiHa}$ and $\mathrm{S} 12$ cells treated with Realgar compared to corresponding control cells. The number of invaded cells decreased significantly after treating with Realgar in both $\mathrm{SiHa}$ and S12 cells. These results indicated that Realgar repressed cell adhesion capacity and the invasiveness of both $\mathrm{SiHa}$ and $\mathrm{S} 12$ cells.

\section{Discussion}

Cancer is a major public health problem and remains the leading cause of death in China. According to "Cancer Statistics in China, 2015", estimated 4,292,000 new cancer cases and 2,814,000 cancer-induced deaths occurred in China in 2015, with $\sim 98,900$ new cases of cervical cancer diagnosed annually, resulting in estimated 30,500 deaths in China. ${ }^{2}$ In contrast to the decreasing incidence trends in the United States (3,240 new cases of cervical cancer, resulting in 4,170 deaths), ${ }^{3}$ an obvious increase in the incidence and death of cervical cancer remained in China. Although the spread of Papanicolaou (Pap) test significantly improved the rate of early diagnosis ${ }^{13}$, China's massive population (1.37 billion) created high incidence and mortality. ${ }^{2}$ The increasing prevalence of high-risk HPV infection and the lack of HPV vaccines in Mainland China were due to the absence of formal drug administration. ${ }^{14}$ Although 
A

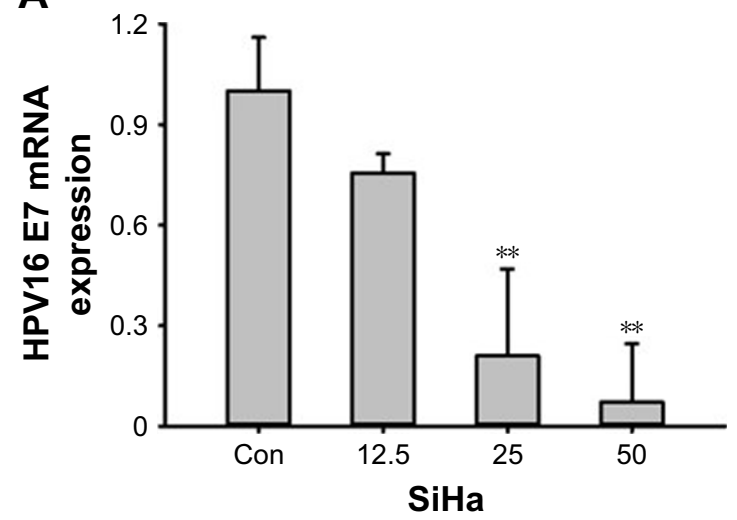

C

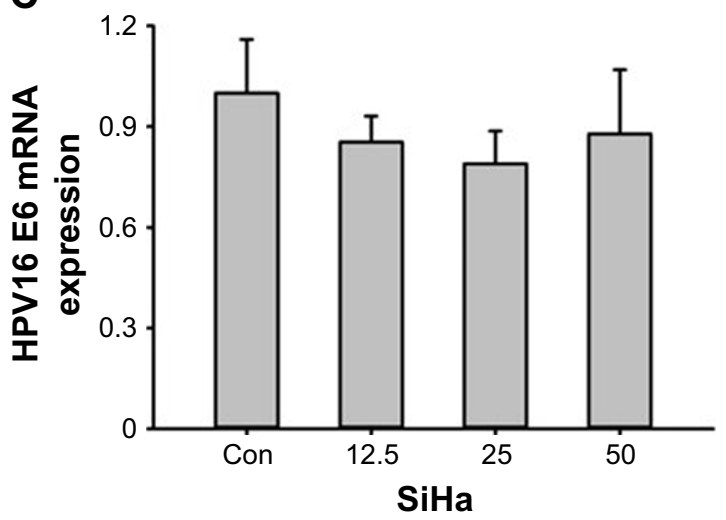

B

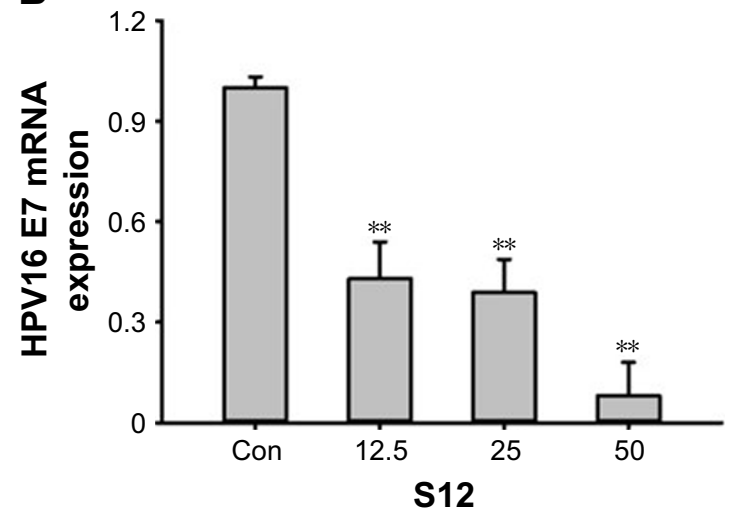

D

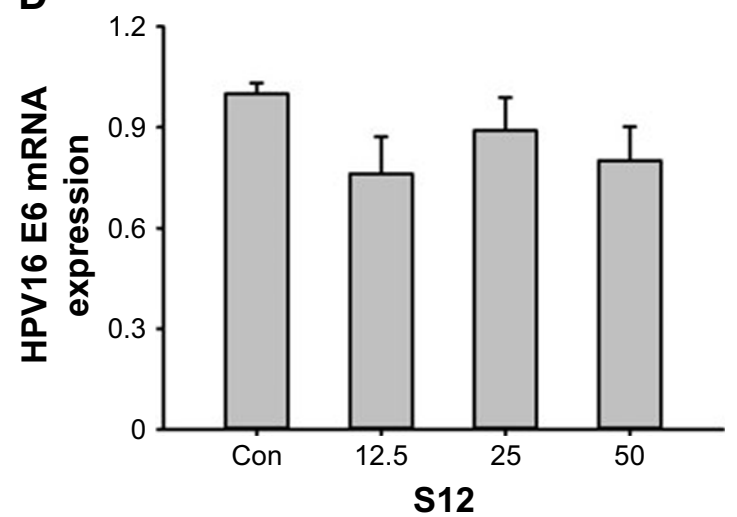

Figure 3 Realgar could downregulate HPVI6 E7 mRNA expression.

Notes: Cells were treated with various concentrations $(\mu \mathrm{g} / \mathrm{mL})$ of Realgar for 48 hours, and then (A and B) HPVI6 E7 and (C and D) HPVI6 E6 mRNA levels were analyzed. GAPDH was used as a reference control. ${ }^{* * P}<<0.01$.

early screening program improves the early diagnosis rate, radical surgery, especially laparoscopic radical resection, for early stages supplemented by chemotherapy and radiotherapy significantly prolonged the overall survival of the patients with cervical carcinoma ${ }^{15}$ and many patients received only incomplete therapy because of the lack of money. Therefore, a new effective and economic strategy for the treatment of cervical cancer is urgently needed.

In China, Realgar was used in the treatment of various diseases including mouth ulcers, tongue ulcers, and headache. ${ }^{11}$ It was reported the activities of Realgar on the induction of apoptosis and the inhibition of proliferation in human ovarian cancer cells, human promyelocytic leukemia HL-60 cells, and human chronic myelogenous leukemia K562 cells. ${ }^{9}$ The data in this study showed that the Realgar dissolved in water significantly inhibited the growth of tumor in a dose-dependent manner, and the conclusion was agreed with the data of this manuscript.

Our data indicated that Realgar induced apoptosis and inhibited the proliferation of both SiHa and S12 cells. Both the cells are HPV16 positive. We found that both HPV16 E7 mRNA expressions were significantly downregulated after incubating with various concentrations of Realgar, while the expression of HPV16 E6 in both the cells seemed to be constant, which indicated that the effects of Realgar may relate to the expression of HPV16 E7. The subsequent experiments showed that Realgar significantly downregulated Bax and caspase-3 in both SiHa and S12 cells and upregulated Bcl-2 in both the cells. The expression of P53 in SiHa cells incubated with various concentrations of Realgar seems irregular, with a nearly twofold increase in P53 mRNA expression by Realgar 12.5 and $50 \mu \mathrm{g} / \mathrm{mL}$ as compared to control, but has no significant change by $25 \mu \mathrm{g} / \mathrm{mL}$ of Realgar. The difference may relate to different apoptosis pathways at various concentrations of reagent. In contrast, we did not found any significant changes in P53 in S12 cells treated with Realgar (Figures 4 and 5). The discrepancy in these data indicated that Realgar may induce cell apoptosis through a non-P53independent pathway, while the protein expression indicated a more complex process. As shown in Figure 6, after treating 
A

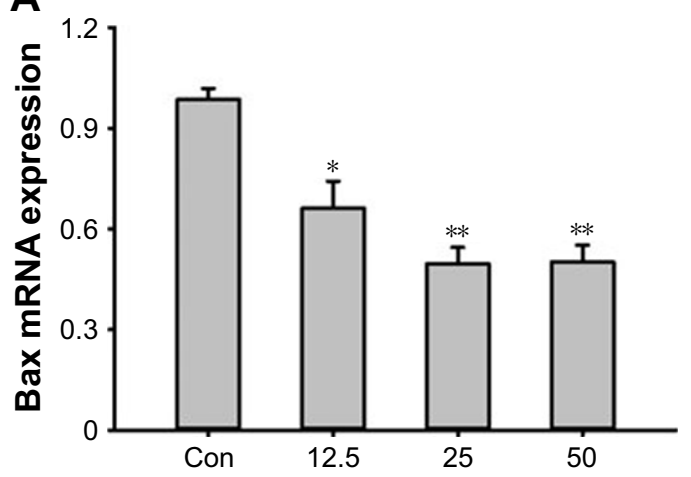

C

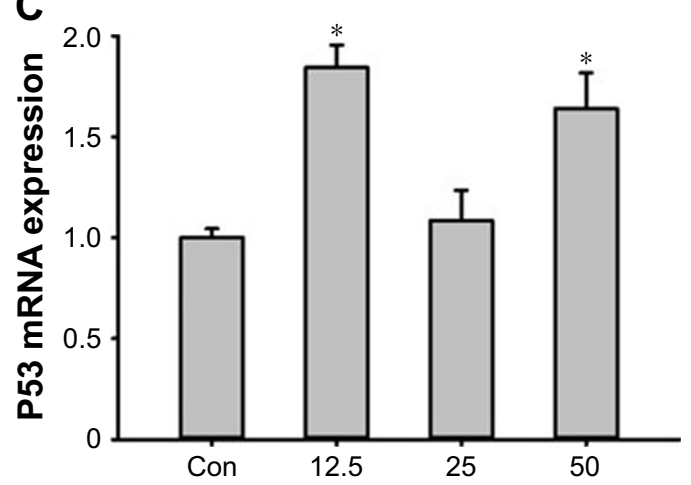

B

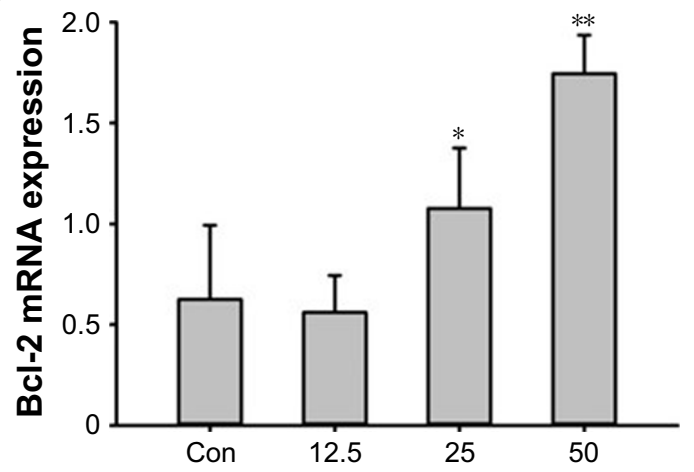

D

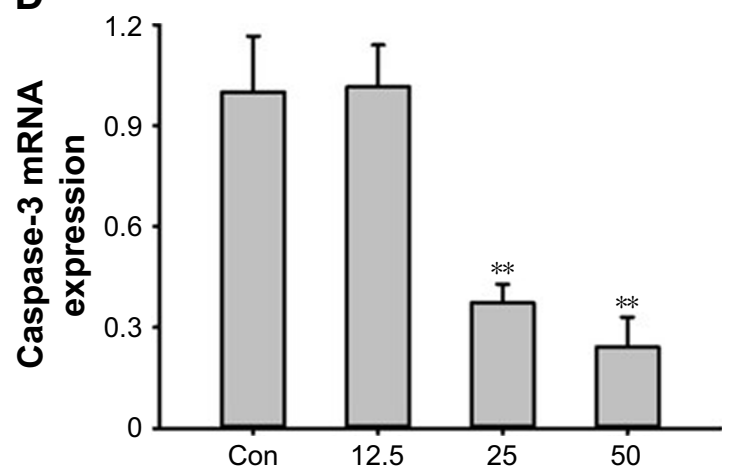

Figure 4 Effects of Realgar on the transcriptional levels of Bax, Bcl-2, P53, and caspase-3 in SiHa cells.

Notes: $\mathrm{SiHa}$ cells were treated with various concentrations $(\mu \mathrm{g} / \mathrm{mL})$ of Realgar for 24 hours. The relative mRNA expression levels of $(\mathbf{A})$ Bax, $(\mathbf{B}) B c l-2$, $(\mathbf{C})$ P53, and (D) caspase-3 genes were detected by quantitative real-time PCR. Values, mean $\pm S D ; * P<0.05$ and $* * P<0.0$ l compared with the untreated control.

with different dosages of Realgar for 48 hours, we found that the expression of HPV16 E7 and Bax in both the cells was markedly downregulated, but the expression of HPV16 E6 was constant in both the cells. Bcl-2, P53, and caspase-3 were substantially upregulated in a lower dose $(25 \mu \mathrm{g} / \mathrm{mL})$ and downregulated in a higher dose $(50 \mu \mathrm{g} / \mathrm{mL})$. These data indicated that Realgar may induce apoptosis and inhibit proliferation through a HPV16 E7-related pathway and bypassing Bax. The raised and decreased expression of Bcl-2, P53, and caspase-3 due to cell apoptosis affected the detected results in Western blotting in a higher dosage $(50 \mu \mathrm{g} / \mathrm{mL})$ of Realgar. In a word, these results indicated that Realgar may induce apoptosis and inhibit the proliferation of $\mathrm{SiHa}$ and S12 cells through a HPV16 E7-related pathway.

HPV16 is a major subtype of infection in China. ${ }^{16}$ Our data considered initially that Realgar is an ideal compound in the
$\mathbf{A}$

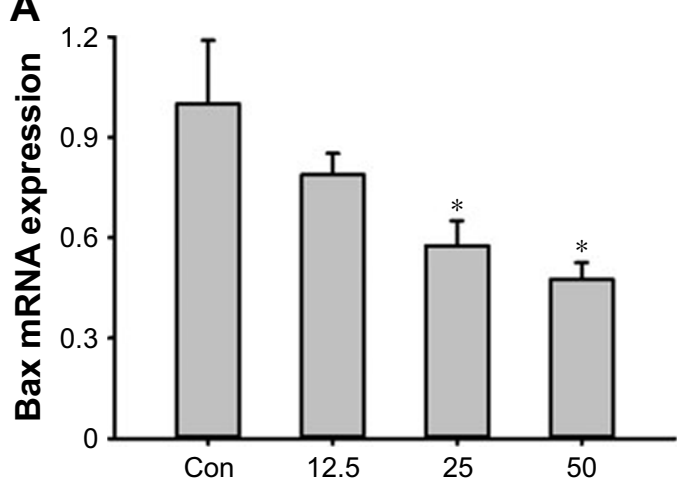

B

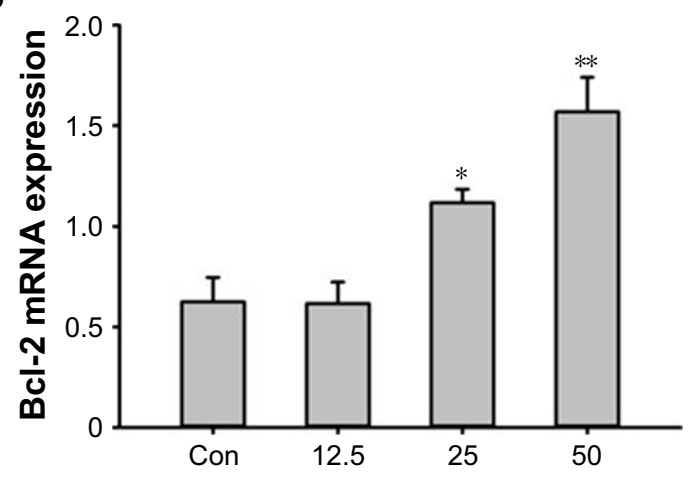

Figure 5 (Continued) 

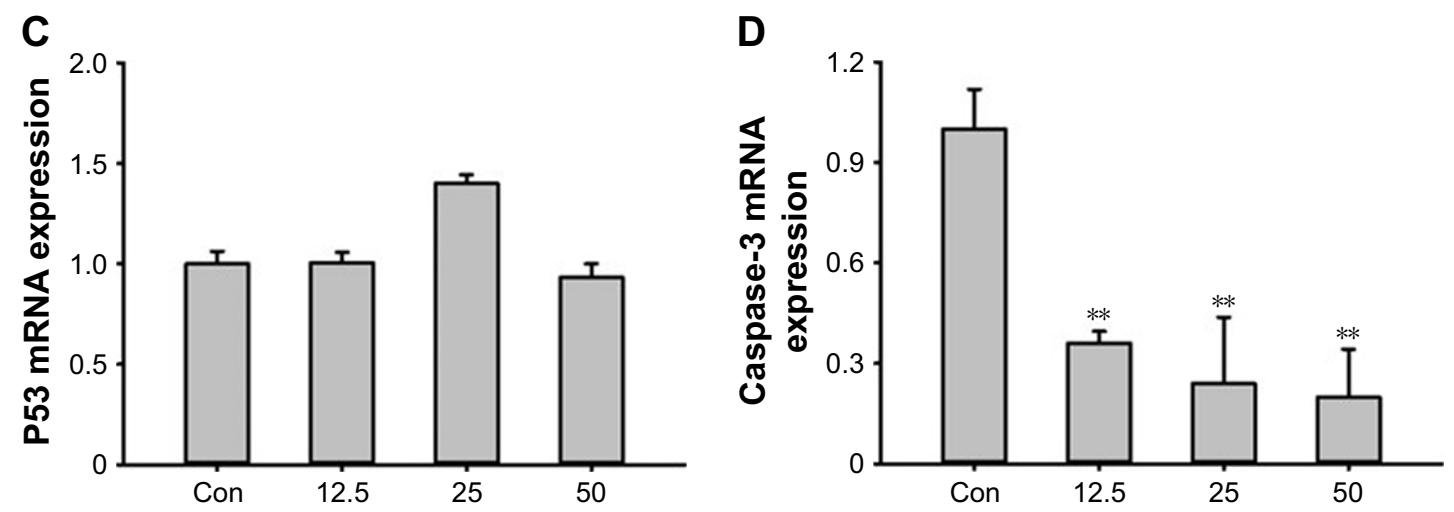

Figure 5 Effects of Realgar on the transcriptional levels of Bax, Bcl-2, P53, and caspase- 3 in SI 2 cells.

Notes: SI 2 cells were treated with various concentrations $(\mu \mathrm{g} / \mathrm{mL})$ of Realgar for 24 hours. The relative mRNA expression levels of (A) Bax, (B) Bcl-2, (C) P53, and (D) caspase-3 genes were detected by quantitative real-time PCR. Values, mean \pm SD; $* P<0.05$ and $* * P<0.01$ compared with the untreated control.

treatment of HPV16 infection-related diseases and cervical cancer. More explorations are needed to improve treatment effects and reduce toxicity. In the treatment of HPV16-related diseases, Realgar exhibits a good prospect of application. This study preliminarily validated the effects of Realgar on the cell apoptosis, proliferation, adhesion, and invasion of $\mathrm{SiHa}$ and S12 cells, and the detailed molecular mechanism still needs to be further explored in subsequent studies.

\section{Conclusion}

The present study indicated that Realgar could effectively inhibit the proliferation and induce the apoptosis of $\mathrm{SiHa}$ and S12 cells through a HPV16 E7-related pathway. It may depend on the activation of Bax, and further exploration of the detailed molecular mechanism is needed. Our data demonstrated that Realgar is a potent cytotoxic agent for HPV16 infectionrelated diseases and may have therapeutic potential.

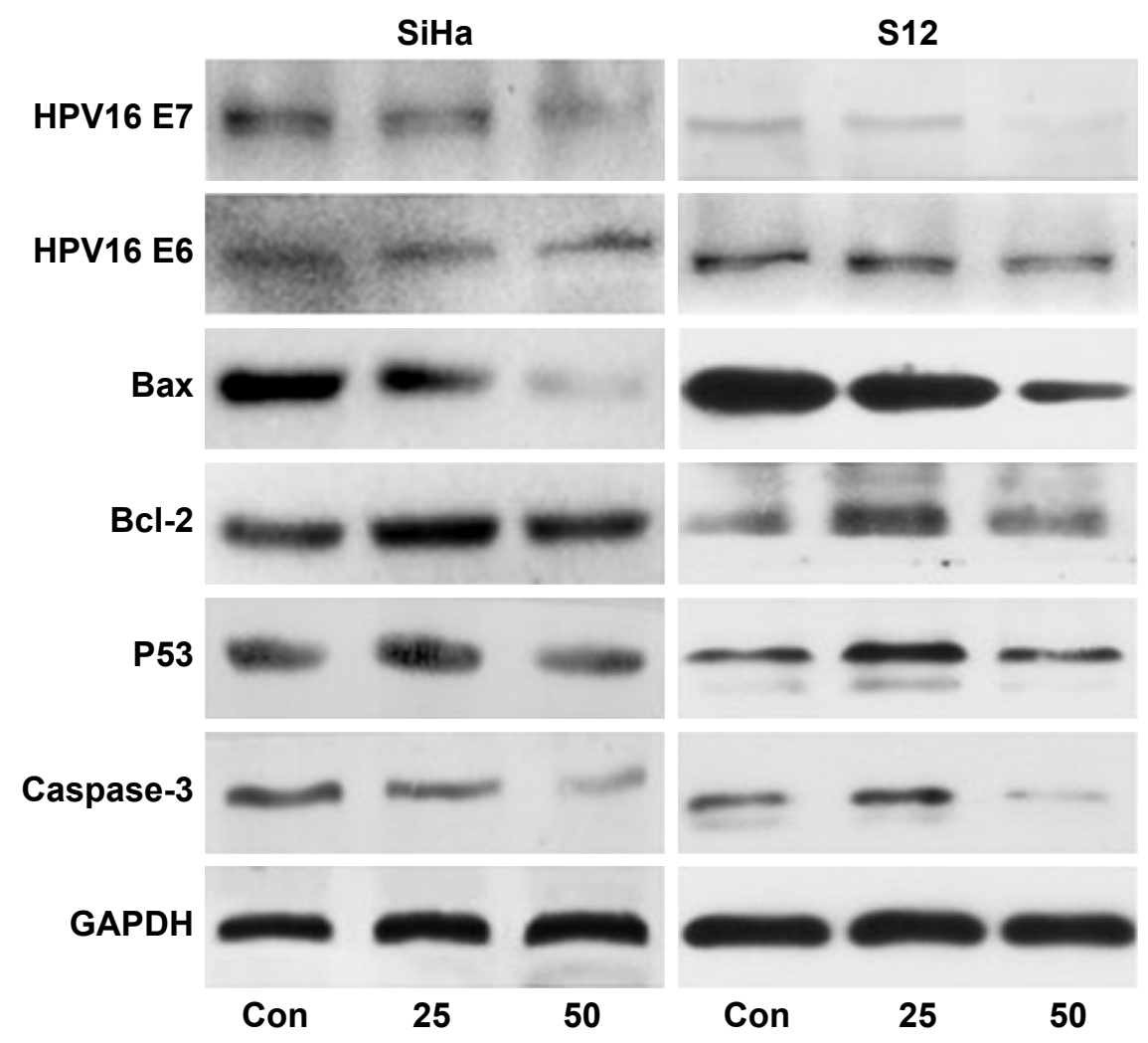

Figure 6 Effects of Realgar on the protein levels in $\mathrm{SiHa}$ and $\mathrm{SI} 2$ cells.

Notes: $\mathrm{SiHa}$ and SI2 cells were treated with 25 and $50 \mu \mathrm{g} / \mathrm{mL}$ of Realgar for 48 hours. The expression levels of HPVI6 E6, E7, Bax, Bcl-2, P53, and caspase-3 proteins were detected by Western blotting. GAPDH was used as an internal control. 


\section{A SiHa}
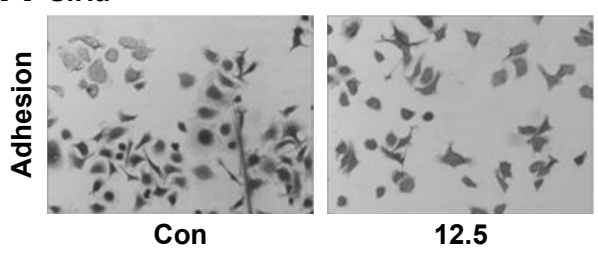

12.5

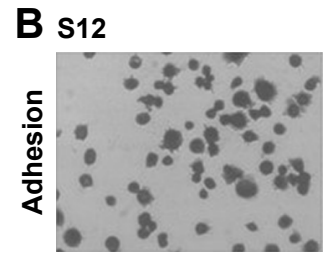

Con

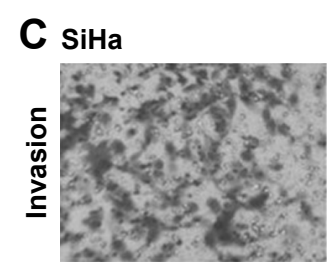

Con

\section{D $\mathrm{S12}$}

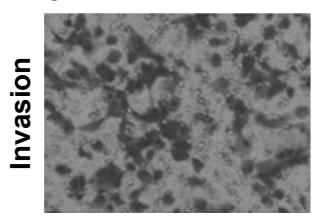

Con

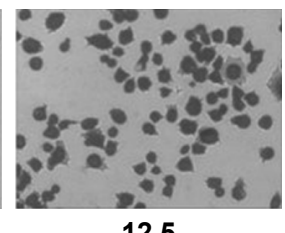

12.5

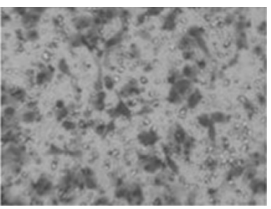

12.5

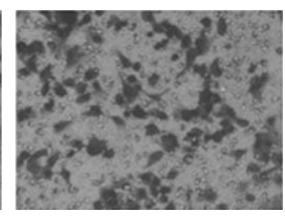

12.5

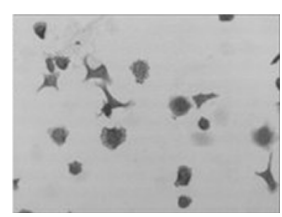

25

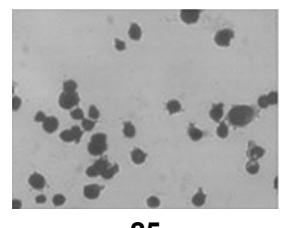

25

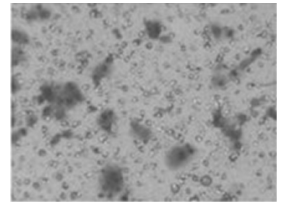

25

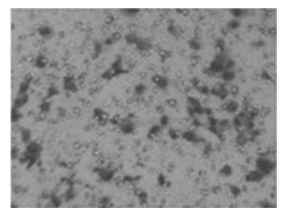

25
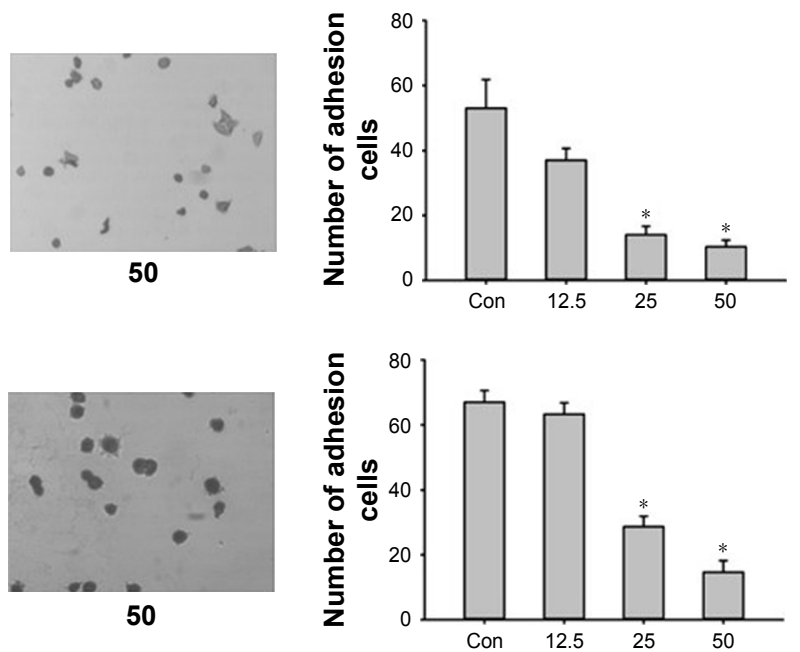

50

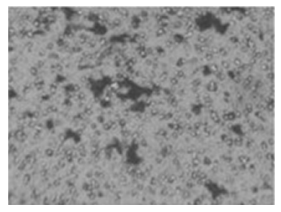

50
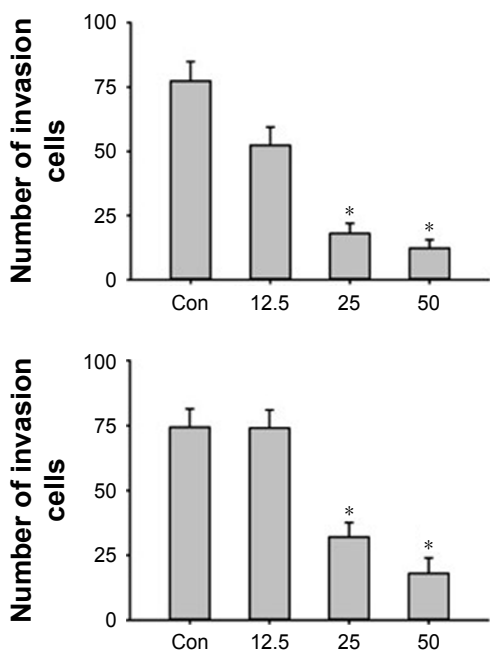

Figure 7 Realgar inhibits cell adhesion and invasion.

Notes: Cell adhesion and invasion assays were performed in the cells treated with various concentrations of Realgar for 48 hours. Representative images of the cell adhesion assays of (A) SiHa and (B) SI2 and quantitative results of the cell adhesion assay are shown. Representative images of the invasion assays of (C) SiHa and (D) SI2 and quantitative results of the invasion assay are shown. $* P<0.05$ vs control.

\section{Acknowledgments}

The authors thank Professor Kenneth Raj (Health Protection Agency, Didcot, UK) for providing the S12 cell line, which was permitted by the primary owner Professor Margaret Stanley (Division of Virology, National Institute for Medical Research, London, UK). This work was supported by funds from the National Natural Science Funding of China (81403166 and 81502252).

\section{Disclosure}

The authors report no conflicts of interest in this work.

\section{References}

1. Ferlay J, Soerjomataram I, Dikshit R, et al. Cancer incidence and mortality worldwide: sources, methods and major patterns in GLOBOCAN 2012. Int J Cancer. 2015;136(5):E359-E386.

2. Chen W, Zheng R, Baade PD, et al. Cancer statistics in China, 2015. CA Cancer J Clin. 2016;66(2):115-132.
3. Siegel RL, Miller KD, Jemal A. Cancer statistics, 2018. CA: A Cancer Journal for Clinicians. 2018;68(1):7-30.

4. Liu J, Lu Y, Wu Q, Goyer RA, Waalkes MP. Mineral arsenicals in traditional medicines: orpiment, realgar, and arsenolite. J Pharmacol Exp Ther. 2008;326(2):363-368.

5. Wu J, Shao Y, Liu J, Chen G, Ho PC, Pc H. The medicinal use of realgar $\left(\mathrm{As}_{4} \mathrm{~S}_{4}\right)$ and its recent development as an anticancer agent. J Ethnopharmacol. 2011;135(3):595-602.

6. Chen GQ, Zhu J, Shi XG, et al. In vitro studies on cellular and molecular mechanisms of arsenic trioxide (As2O3) in the treatment of acute promyelocytic leukemia: As2O3 induces NB4 cell apoptosis with downregulation of Bcl-2 expression and modulation of PML-RAR alpha/PML proteins. Blood. 1996;88(3):1052-1061.

7. Shen ZX, Chen GQ, Ni JH, et al. Use of arsenic trioxide (As2O3) in the treatment of acute promyelocytic leukemia (APL): II. Clinical efficacy and pharmacokinetics in relapsed patients. Blood. 1997;89(9): 3354-3360.

8. Lu DP, Qiu JY, Jiang B, et al. Tetra-arsenic tetra-sulfide for the treatment of acute promyelocytic leukemia: a pilot report. Blood. 2002;99(9): 3136-3143.

9. Ding W, Zhang L, Kim S, et al. Arsenic sulfide as a potential anti-cancer drug. Mol Med Rep. 2015;11(2):968-974. 
10. Zhang L, Kim S, Ding W, et al. Arsenic sulfide inhibits cell migration and invasion of gastric cancer in vitro and in vivo. Drug Des Devel Ther. 2015;9:5579-5590.

11. Zhang L, Tian W, Kim S, Ding W, Tong Y, Chen S. Arsenic sulfide, the main component of realgar, a traditional Chinese medicine, induces apoptosis of gastric cancer cells in vitro and in vivo. Drug Des Devel Ther. 2015;9:79-92.

12. Stanley MA, Browne HM, Appleby M, Minson AC. Properties of a nontumorigenic human cervical keratinocyte cell line. Int J Cancer. 1989; 43(4):672-676.

13. Naucler P, Ryd W, Törnberg S, et al. Human papillomavirus and Papanicolaou tests to screen for cervical cancer. N Engl J Med. 2007;357(16): 1589-1597.
14. Li J, Huang R, Schmidt JE, Qiao YL. Epidemiological features of Human Papillomavirus (HPV) infection among women living in Mainland China. Asian Pac J Cancer Prev. 2013;14(7):4015-4023.

15. Gupta S, Maheshwari A, Parab P, et al. Neoadjuvant Chemotherapy Followed by Radical Surgery Versus Concomitant Chemotherapy and Radiotherapy in Patients With Stage IB2, IIA, or IIB Squamous Cervical Cancer: A Randomized Controlled Trial. J Clin Oncol. 2018;36(16):1548-1555.

16. Di J, Rutherford S, Chu C. Review of the Cervical Cancer Burden and Population-Based Cervical Cancer Screening in China. Asian Pac J Cancer Prev. 2015;16(17):7401-7407. 


\section{Supplementary material}

Table SI Primer sequences used in real-time PCR

\begin{tabular}{|c|c|c|c|}
\hline Primer ID & Direction & Primer sequences & $\begin{array}{l}\text { Length } \\
\text { (bp) }\end{array}$ \\
\hline \multirow[t]{2}{*}{$\mathrm{P} 53$} & $\mathrm{~F}$ & 5'-GCTTTGAGGTGCGTGTTTGTG-3' & 125 \\
\hline & $\mathrm{R}$ & 5'-GTTGGGCAGTGCTCGCTTAG-3' & \\
\hline \multirow[t]{2}{*}{$\mathrm{Bcl}-2$} & $\mathrm{~F}$ & 5'-ATCGCCCTGTGGATGACTGA-3' & 133 \\
\hline & $\mathrm{R}$ & 5'-GAGACAGCCAGGAGAAATCAAAC- $3^{\prime}$ & \\
\hline \multirow[t]{2}{*}{ Bax } & $\mathrm{F}$ & 5'-TTTTGCTTCAGGGTTTCATCCA-3' & 215 \\
\hline & $\mathrm{R}$ & 5'-TGCCACTCGGAAAAAGACCTC-3' & \\
\hline \multirow[t]{2}{*}{ Caspase-3 } & $\mathrm{F}$ & 5'-TGGAAGCGAATCAATGGACTCT-3' & 170 \\
\hline & $\mathrm{R}$ & 5'-TGAATGTTTCCCTGAGGTTTGC-3' & \\
\hline \multirow[t]{2}{*}{ HPVI6 E7 } & $\mathrm{F}$ & 5'-AGCAATTAAATGACAGCTCAGAGG-3' & 127 \\
\hline & $\mathrm{R}$ & 5'-CACAACCGAAGCGTAGAGTCAC-3' & \\
\hline \multirow[t]{2}{*}{ GAPDH } & $\mathrm{F}$ & 5'-ACTTTGGTATCGTGGAAGGACTCAT-3' & 255 \\
\hline & $\mathrm{R}$ & 5'-GTTTTTCTAGACGGCAGGTCAGG-3' & \\
\hline
\end{tabular}

Abbreviations: F, forward; R, reverse.

\section{Publish your work in this journal}

Drug Design, Development and Therapy is an international, peerreviewed open-access journal that spans the spectrum of drug design and development through to clinical applications. Clinical outcomes, patient safety, and programs for the development and effective, safe, and sustained use of medicines are the features of the journal, which has also been accepted for indexing on PubMed Central. The manuscript management system is completely online and includes a very quick and fair peer-review system, which is all easy to use. Visit http://www.dovepress.com/testimonials.php to read real quotes from published authors.

Submit your manuscript here: http://www.dovepress.com/drug-design-development-and-therapy-journal 